\title{
Progression Analysis with ABCD Grading System following Corneal Collagen Cross-Linking in Keratoconus
}

\author{
(D) Ayhan Saglik, ${ }^{1}$ (1) Mehmed Ugur Isik ${ }^{2}$ \\ 1Department of Ophthalmology, Harran University, Sanliurfa, Turkey \\ ${ }^{2}$ Department of Ophthalmology, Balikligol State Hospital, Sanliurfa, Turkey
}

\begin{abstract}
Objectives: To evaluate the $A B C D$ grading system used in follow-up of keratoconus progression after the corneal collagen cross-linking (CXL) treatment in different Kmax groups.

Methods: This study included 57 eyes of 43 patients applied with CXL treatment for progressive keratoconus. All the patients were applied with the standard CXL protocol (Dresden). According to the changes in the Kmax value at the end of 12 months postoperatively $(0-I D, I-2 D,>2 D)$, the groups were separated as steepening and flattening. Scheimpflug progression parameters, such as $A B C D$ keratoconus grading systems, were evaluated in six different groups. The Paired Samples t-test was used in the evaluation of parameters with normal distribution and the Wilcoxon test for parameters not showing normal distribution. A value of $\mathrm{p}<0.05$ was accepted as statistically significant.

Results: Mean age of patients was $18.37 \pm 3.86$ years (I I-28 years). According to the ABCD grading system, 0.19 significant regression was determined in grade $A(p=0.014)$ and 0.24 in grade $D(p<0.0001) .0 .10$ progression was seen in grade $B(p=0.089)$, and $0.1 I$ in grade $C(p=0.011)$. In the mean $K \max$ value $0.25 \pm 0.42$, $D$ flattening was seen $(p=0.137)$.

Conclusion: The anterior corneal surface grade in $A B C D$ system is correlated with Kmax in different groups. However, the posterior corneal surface parameter is not correlated with Kmax in I-2 D steepening and >2D flattening groups. Although there is an increase in posterior elevation after $C X L$, despite excessive $\mathrm{Kmax}$ flattening, it would be inaccurate to consider this increase as an indicator of topographic progress.
\end{abstract}

Keywords: $A B C D$ grading system, cross-linking, keratoconus, maximum keratometry, progression analysis.

\section{Introduction}

Keratoconus is a corneal ectasia that may lead to irregular astigmatism, progressive corneal thinning and corneal scarring. Keratoconus generally starts in puberty and progression can show variability from patient to patient $(I, 2)$.

Riboflavin and ultraviolet-A-induced corneal collagen cross-linking $(\mathrm{CXL})$ treatment is a surgical procedure that has been applied for more than 10 years to slow the progression of keratoconus. Cross-linkages photochemically activated within the stromal collagen network increase the biochemical stability of the cornea (3-5). The clinical and topographic findings of several studies have shown that $\mathrm{CXL}$ treatment slows the progression of keratoconus (6-8).

There are currently several corneal analysis methods, such as keratometry, pachymetry, topography and tomography, which have an important place in the diagnosis of keratoconus and in follow-up after CXL treatment (9). In addition, a clearer and more sensitive analysis can be obtained 
of ectasic changes in the cornea using anterior and posterior elevation data and pachymetric data of the Belin-Ambrosio Enhanced Ectrasia Display (BAD) (available on the Pentacam, OCULUS GmbH, Wetzlar, Germany) (10, II).

This study aims to evaluate the $A B C D$ grading system used in follow-up of keratoconus progression after the corneal cross-linking treatment in different Kmax groups. The findings of the study can be considered as important guidance in respect of the comparison of topographic parameters commonly used in the follow-up of the progression of keratoconus.

\section{Methods}

\section{Study Population}

This retrospective study included 57 eyes of 43 patients applied with CXL treatment for progressive keratoconus in the Ophthalmology Department between December 2016 and October 2018. Approval for the study was granted by the Local Ethics Committee and all procedures were conducted in accordance with the Helsinki Declaration (Ethics acceptance no: 18/05/21). Written informed consent for publication of this clinical details and/or clinical images was obtained from the patient. A copy of the consent form is available for review by the Editor of this journal.

The diagnosis of keratoconus was made from tomography findings, such as asymmetric bow-tie pattern and inferior-superior (I-S) asymmetry obtained with Scheimpflug imaging (Pentacam HR; Oculus GmbH, Wetzlar, Germany).

\section{Inclusion and Exclusion Criteria}

Only patients with progressive keratoconus were included in this study. An increase of >ID in the Kmax value between two consecutive examinations (at least six months of followup) before corneal CXL treatment was accepted as progression criteria.

Patients were excluded from this study if the thinnest corneal thickness (pachymin) obtained on Scheimpflug imaging was $<400 \mu \mathrm{m}$, if they had excessive axial corneal scarring, ocular trauma, a history of ocular surgery, herpetic keratitis, any autoimmune disease, were pregnant, or had used contact lenses within the previous month.

\section{Preoperative and Postoperative Measurements}

Measurements of all the eyes included in this study were taken with a Pentacam HR (OCULUS GmbH, Wetzlar, Germany). Patients had stopped wearing contact lenses at least one month before the measurements. The Scheimpflug images were obtained by a single researcher experienced in this procedure in the Cornea Unit of Ophthalmology Department. If the image quality was not automatically checked and labelled as "OK", the evaluation was repeated.
Only the images which passed the quality control as "OK" were included in this study. This approach provided greater reliability of the measurements. At least two measurements were taken from all patients to assess repeatability. The variables used for follow-up of progression after CXL treatment were measured before $C X L$ and at 12 months after CXL. The differences between the measurements were analysed.

According to the changes in the Kmax value at the end of 12 months postoperatively (0-ID, I-2D, and >2D), the groups were separated as steepening and flattening. In the follow-up of progression, the $A B C D$ keratoconus grading system was used, which was scored from 0 to 4 by the Pentacam (10). The letters used in this grading system correspond to the following: "A" calculated from ARC (corneal curvature at $3 \mathrm{~mm}$ from the thinnest point on the anterior corneal surface), "B" calculated from PRC (corneal curvature at 3 $\mathrm{mm}$ from the thinnest point on the posterior corneal surface), "C" calculated from pachymin (thinnest pachymetry), and "D" (Distance best corrected vision) (Table I). After the CXL treatment, increases in these parameters were considered as progression while decreases were considered as regression.

The parameters were examined of Kmax, minimum pachymetry (Pachymin), front elevation in thinnest location (F.ele.th.), back elevation in thinnest location (B.ele.th.) and the Ambrósio relational thickness maximum (ARTmax) value, calculated using the formula below (I2):

$$
\mathrm{ART}_{\text {max }}=\frac{\mathrm{Tp}}{\text { PPimax }}
$$

Tp: Thinnest pachymetry

$\mathrm{PPi}_{\text {max }}:$ Pachymetric progression index maximum

\section{Surgical Technique}

All the patients were applied with the standard CXL procedure as defined by Wollensack et al. (13) Anaesthesia was provided before the procedure with proparacaine hydrochloride $0.5 \%$, then, $0.9 \mathrm{~mm}$ corneal epithelium was separated using a crescent knife. After corneal thickness measurement with ultrasonic pachymetry (UP), isotonic riboflavin (0.1\% Riboflavin with 20\% Dextran T500) (Collagex, Taipei, Taiwan) was droppered at 2-min intervals for 30 mins. Riboflavin absorption in the anterior chamber was checked with a slit-lamp biomicroscope, then, measurements were taken again with UP.

Before the UVA process, if the corneal thickness thinner from $400 \mu \mathrm{m}$, a hypotonic riboflavin solution $(0.1 \%$ in sterile water) (Collagex, Taipei, Taiwan) was applied as I drop every 10 seconds for 2 mins.

When the corneal stromal thickness was seen to be $\geq 400 \mu \mathrm{m}$ with UP, UVA light of $365 \mathrm{~nm}$ (LightLink-CXL, 
Table I. Proposed ABCD keratoconus grading system (10)

\begin{tabular}{|c|c|c|c|c|}
\hline ABCD criteria & $\begin{array}{c}\text { A } \\
\text { ARC } \\
\text { (3 mm zone) }\end{array}$ & $\begin{array}{c}\text { B } \\
\text { PRC } \\
\text { (3 mm zone) }\end{array}$ & $\begin{array}{c}\text { C } \\
\text { Thinnest pach } \\
(\mu \mathrm{m})\end{array}$ & $\begin{array}{c}\text { D } \\
\text { BDVA }\end{array}$ \\
\hline Stage 0 & $\begin{array}{c}7.25 \mathrm{~mm} \\
(<46.5 \mathrm{D})\end{array}$ & $>5.90 \mathrm{~mm}$ & $>490 \mu \mathrm{m}$ & $\begin{array}{c}\geq 20 / 20 \\
(\geq 1.0)\end{array}$ \\
\hline Stage I & $\begin{array}{l}7.05 \mathrm{~mm} \\
(<48.0 \mathrm{D})\end{array}$ & $>5.70 \mathrm{~mm}$ & $>450 \mu \mathrm{m}$ & $\begin{array}{l}<20 / 20 \\
(<1.0)\end{array}$ \\
\hline Stage II & $\begin{array}{l}>6.35 \mathrm{~mm} \\
(<53.0 \mathrm{D})\end{array}$ & $>5.15 \mathrm{~mm}$ & $>400 \mu \mathrm{m}$ & $\begin{array}{c}<20 / 40 \\
(<0.5)\end{array}$ \\
\hline Stage III & $\begin{array}{l}>6.15 \mathrm{~mm} \\
(<55.0 \mathrm{D})\end{array}$ & $>4.95 \mathrm{~mm}$ & $>300 \mu \mathrm{m}$ & $\begin{array}{c}<20 / 100 \\
(<0.2)\end{array}$ \\
\hline Stage IV & $\begin{array}{l}6.15 \mathrm{~mm} \\
(>55.0 \mathrm{D})\end{array}$ & $<4.95 \mathrm{~mm}$ & $\leq 300 \mu \mathrm{m}$ & $\begin{array}{l}<20 / 400 \\
(<0.05)\end{array}$ \\
\hline
\end{tabular}

Stages ( 0 to IV) are based on anterior and posterior radius of curvature (ARC, PRC), thinnest pachymetry, best corrected distance visual acuity (BDVA). ARC: corneal curvature at $3 \mathrm{~mm}$ from the thinnest point on the anterior corneal surface, PRC: corneal curvature at $3 \mathrm{~mm}$ from the thinnest point on the posterior corneal surface, thinnest pach: thinnest pachymetry.

LIGHTMED, Taiwan) was applied at irradiance of $3.0 \mathrm{~mW} /$ $\mathrm{cm}^{2}$ for 30 mins. In cases where hypotonic riboflavin was required, a hypotonic riboflavin solution was continued every two minutes during the application of UVA.

Postoperatively, a soft contact lens was applied and topical antibiotic drops were used four times a day. Following epithelial healing, the lens were removed and topical steroid treatment was started at the dose of four times a day for two weeks and this was continued for up to three months with a gradually tapering dose.

\section{Statistical Analysis}

The comparisons of the first and second measurements were statistically analysed using SPSS vn 24 (IBM). For evaluation of repeatability, the intraclass correlation coefficient (ICC) and its $95 \%$ confident interval $(\mathrm{Cl})$ were determined. An ICC greater than 0.7 is considered acceptable, greater than 0.8 is considered good, and greater than 0.9 is considered excellent (14). Furthermore, heat map analysis was performed to examine the distribution of the data in all patients. Conformity of the data to normal distribution was assessed using the Shapiro-Wilk test. Descriptive statistics (mean \pm standard deviation) were used in the evaluation of data with normal distribution, and data not showing normal distribution were stated as median and interquartile range (IQR) values. The Paired Samples t-test was used in the evaluation of parameters with normal distribution and the Wilcoxon test for parameters not showing normal distribution. A value of $p<0.05$ was accepted as statistically significant.

\section{Results}

In this study, 23 female and 20 male patients with a mean age of $18.37 \pm 3.86$ years (I I-28 years); 19 (44\%) patients were aged $<18$ years and $24(56 \%)$ were $>18$ years were involved. The eyes treated in this study were $30(53 \%)$ right-side and $27(47 \%)$ left-side. The application of hypotonic riboflavin solution was necessary in six $(10 \%)$ eyes.

The topographic parameters before CXL and at I 2 months postoperatively of all the patients are shown in Table 2 . The ICC and its $95 \% \mathrm{Cl}$ were found greater than 0.9 in repeatability analysis of different Kmax measurements. In the mean $K \max$ value $0.25 \pm 0.42 \mathrm{D}$ flattening was seen $(p=0.137)$. A statistically significant reduction was determined in the $A$ grade, $D$ grade, pachymin, F.ele.th, and ARTmax values $(p=0.014$, $p<0.000$ I, $p=0.005, p=0.008, p=0.024$, respectively). A statistically significant increase was determined in the ARC and $C$ grade ( $p=0.007, p=0.004$, respectively). According to the $A B C D$ grading system, statistically significant regression was determined in grade $A(p=0.014)$ and grade $D(p<0.0001)$. Significant progression was seen in grade $C(p=0.004)$ (Table 2).

The topographic progression parameters evaluated according to the change in the Kmax value and the 12-month follow-up period are shown in Table 3 and Table 4. In the Kmax values, 0-ID flattening was determined in 21 (37\%) eyes, I-2D flattening in nine $(16 \%)$ eyes and $\geq 2 \mathrm{D}$ flattening in four $(7 \%)$ eyes. Steepening of $0-I D$ was determined in the Kmax values of 13 (23\%) eyes, I-2D in nine (16\%) eyes, and 22D in one ( $1 \%)$ eye. Particularly in $>2 \mathrm{D}$ flattening group, abnormal measurements between $A B C D$ grading system 
Table 2. Mean values and differences of topographic indices before and after $C X L$ treatment

\begin{tabular}{lcccc} 
& Pre-CXL & Post-CXL month I 2 & Mean Difference & P \\
\hline Kmax $(\mathrm{D})$ & $55.88 \pm 5.23$ & $55.63 \pm 5.29$ & $-0.25 \pm 0.42$ & $=0.137$ \\
Pachymin $(\mu \mathrm{m})$ & $447.30 \pm 35.84$ & $440.81 \pm 37.37$ & $-6.66 \pm 17.16$ & $=0.005^{*}$ \\
ARC $(\mathrm{mm})$ & $6.60 \pm 0.44$ & $6.70 \pm 0.49$ & $0.08 \pm 0.23$ & $=0.007^{*}$ \\
PRC $(\mathrm{mm})$ & $5.00 \pm 0.43$ & $4.99 \pm 0.45$ & $-0.01 \pm 0.10$ & $=0.152$ \\
A & $2.83 \pm 1.31$ & $2.60 \pm 1.36$ & $-0.19 \pm 0.56$ & $=0.014^{*}$ \\
B & $4.04 \pm 1.80$ & $4.13 \pm 1.86$ & $0.10 \pm 0.47$ & $=0.102$ \\
C & $1.98 \pm 0.72$ & $2.12 \pm 0.73$ & $0.13 \pm 0.34$ & $=0.004^{*}$ \\
D & $2.57 \pm 0.80$ & $2.32 \pm 0.75$ & $-0.24 \pm 0.42$ & $<0.000 I^{*}$ \\
ARTmax & $166.61 \pm 44.17$ & $158.59 \pm 46.95$ & $-8.01 \pm 26.04$ & $=0.024^{*}$ \\
F.ele.Th. $(\mu \mathrm{m})$ & $21.83 \pm 8.38$ & $18.87 \pm 9.06$ & $-2.04 \pm 5.66$ & $=0.008^{*}$ \\
B.ele.Th. $(\mu \mathrm{m})$ & $44.83 \pm 16.76$ & $45.00 \pm 17.25$ & $0.21 \pm 5.38$ & $=0.769$ \\
\hline
\end{tabular}

*statistically significant $(\mathrm{p}<0.05)$; Kmax: maximum keratometry, ARC: corneal curvature at $3 \mathrm{~mm}$ from the thinnest point on the anterior corneal surface, PRC: corneal curvature at $3 \mathrm{~mm}$ from the thinnest point on the posterior corneal surface, pachymin: thinnest pachymetry, Fele.th: front elevation in thinnest location, B.ele.th: back elevation in thinnest location, ARTmax:Ambrósio relational thickness maximum.

were observed. While there was 0.95 regression in the grade $A$ and 0.32 regression in the grade $D, 0.43$ progression was determined in grade $B$ and 0.42 progression in grade $C$. (Fig. I), (Table 4).

Table 3. Mean differences of topographic indices after CXL treatment in Kmax steepening groups

\begin{tabular}{|c|c|c|}
\hline & $\begin{array}{c}K \max 0-I D T \\
(n=13)\end{array}$ & $\begin{array}{c}K \max I-2 D \\
(n=9)\end{array}$ \\
\hline Age & $18.58 \pm 4.67$ & $18.20 \pm 1.32$ \\
\hline$M-K \max (D)$ & $56.63 \pm 5.11$ & $55.13 \pm 3.70$ \\
\hline (Range) & $(49.20-66.80)$ & $(49.40-61.10)$ \\
\hline $\mathrm{Kmax}(\mathrm{D})$ & $0.38 \pm 0.25$ & $1.33 \pm 0.31$ \\
\hline Pachymin $(\mu \mathrm{m})$ & $-0.15 \pm 11.43$ & $-10.50 \pm 14.78$ \\
\hline $\operatorname{ARC}(\mathrm{mm})$ & $-0.02 \pm 0.09$ & $0.03 \pm 0.21$ \\
\hline $\operatorname{PRC}(\mathrm{mm})$ & $-0.02 \pm 0.08$ & $0.006 \pm 0.12$ \\
\hline$A$ & $0.03 \pm 0.40$ & $0.14 \pm 0.55$ \\
\hline B & $0.15 \pm 0.38$ & $-0.01 \pm 0.58$ \\
\hline C & $0.01 \pm 0.15$ & $0.21 \pm 0.30$ \\
\hline D & $-0.27 \pm 0.38$ & $-0.28 \pm 0.34$ \\
\hline ARTmax & $-2.84 \pm 15.23$ & $-5.50 \pm 22.03$ \\
\hline F.ele.th. $(\mu \mathrm{m})$ & $-0.05 \pm 1.94$ & $-1.70 \pm 5.14$ \\
\hline B.ele.th. $(\mu \mathrm{m})$ & $1.6 I \pm 5.66$ & $-2.70 \pm 4.80$ \\
\hline \multicolumn{3}{|c|}{$\begin{array}{l}\text { Kmax: maximum keratometry, Kmax UC: Kmax unchanged group, M-Kmax: } \\
\text { mean maximum keratometry, ARC: corneal curvature at } 3 \mathrm{~mm} \text { from the } \\
\text { thinnest point on the anterior corneal surface, PRC: corneal curvature at } 3 \mathrm{~mm} \\
\text { from the thinnest point on the posterior corneal surface, pachymin: thinnest } \\
\text { pachymetry, Fele.th: front elevation in thinnest location, B.ele.th: back elevation } \\
\text { in thinnest location,ARTmax:Ambrósio relational thickness maximum. }\end{array}$} \\
\hline
\end{tabular}

Considering the difference between the initial and final values, there was no significant relationship between the change in $\mathrm{Kmax}$ values and the change in the stages of $B$ and $C$ grades. However, there was a significant corelation between the change in $K \max$ values and the change of $A$ grade (Table 5).

No reduction in CDVA was determined in any eye at the end of 12 months. In one patient who developed grade 2-3 haze, and an increase of 2.3D was observed in the Kmax value. The preoperative and postoperative Scheimpflug BAD analyses of this patient are presented in Figure 2.

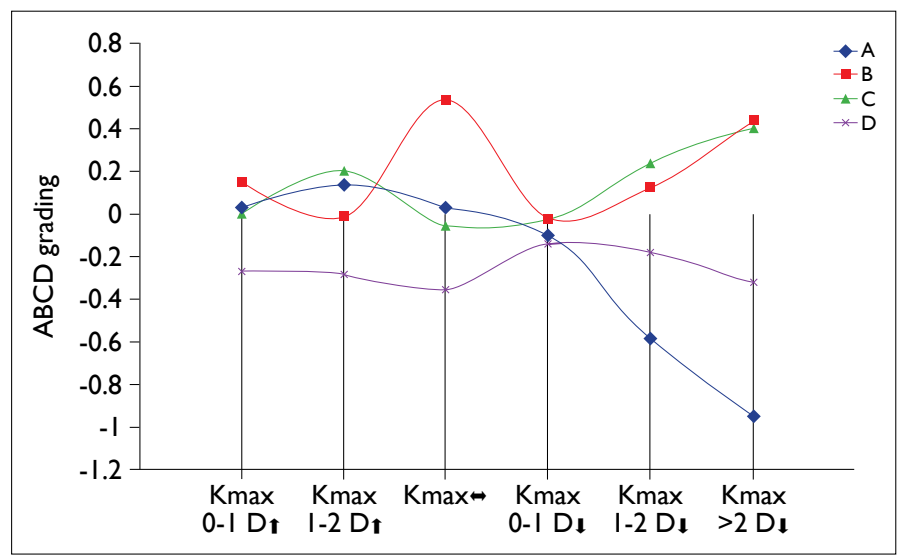

Figure I. Evaluation of different Kmax groups according to $A B C D$ grading system.

Kmax: maximum keratometry, $A$ : corneal curvature at $3 \mathrm{~mm}$ from the thinnest point on the anterior corneal surface (ARC), B: corneal curvature at $3 \mathrm{~mm}$ from the thinnest point on the posterior corneal surface (PRC) and C: thinnest pachymetry (pachymin). 
Table 4. Mean differences of topographic indices after CXL treatment in Kmax flattening groups

\begin{tabular}{|c|c|c|c|}
\hline & $\begin{array}{c}K \max 0-I D \perp \\
(n=2 I)\end{array}$ & $\begin{array}{c}K \max I-2 D \\
(n=9)\end{array}$ & $\begin{array}{c}K \max >2 D \\
(n=4)\end{array}$ \\
\hline Age & $19.22 \pm 3.93$ & $17.44 \pm 2.29$ & $17.25 \pm 1.25$ \\
\hline$M-K \max (D)$ & $55.53 \pm 5.13$ & $56.97 \pm 6.41$ & $56.62 \pm 8.92$ \\
\hline (Range) & $(48.30-63.90)$ & $(50.20-70.40)$ & $(50.90-70.00)$ \\
\hline Kmax (D) & $-0.44 \pm 0.35$ & $-1.37 \pm 0.27$ & $-3.22 \pm 1.02$ \\
\hline Pachymin $(\mu \mathrm{m})$ & $0.04 \pm 11.38$ & $-8.44 \pm 7.61$ & $-19.00 \pm 17.60$ \\
\hline $\mathrm{ARC}(\mathrm{mm})$ & $0.03 \pm 0.05$ & $0.12 \pm 0.07$ & $0.27 \pm 0.25$ \\
\hline PRC (mm) & $0.001 \pm 0.07$ & $0.001 \pm 0.55$ & $-0.10 \pm 0.15$ \\
\hline$A$ & $-0.10 \pm 0.19$ & $-0.43 \pm 0.32$ & $-0.95 \pm 0.74$ \\
\hline B & $-0.002 \pm 0.31$ & $0.004 \pm 0.24$ & $0.43 \pm 0.75$ \\
\hline C & $-0.003 \pm 0.23$ & $0.16 \pm 0.14$ & $0.42 \pm 0.43$ \\
\hline $\mathrm{D}$ & $-0.14 \pm 0.40$ & $-0.18 \pm 0.33$ & $-0.32 \pm 0.25$ \\
\hline ARTmax & $4.76 \pm 18.70$ & $-|8|.| \pm| 8.75$ & $-54.00 \pm 34.14$ \\
\hline F.ele.th. $(\mu \mathrm{m})$ & $-0.85 \pm 2.47$ & $-2.66 \pm 2.95$ & $-6.00 \pm 5.29$ \\
\hline B.ele.th. $(\mu \mathrm{m})$ & $-0.09 \pm 5.69$ & $-0.11 \pm 5.25$ & $2.75 \pm 5.90$ \\
\hline
\end{tabular}

Kmax: maximum keratometry, Kmax UC: Kmax unchanged group, M-Kmax: mean maximum keratometry, ARC: corneal curvature at $3 \mathrm{~mm}$ from the thinnest point on the anterior corneal surface, PRC: corneal curvature at $3 \mathrm{~mm}$ from the thinnest point on the posterior corneal surface, pachymin: thinnest pachymetry, Feele.th: front elevation in thinnest location, B.ele.th: back elevation in thinnest location, ARTmax:Ambrósio relational thickness maximum.

Table 5. Correlation between $\mathrm{Kmax}$ and A, B, and C grades in differences between baseline and I 2 th month

\begin{tabular}{|c|c|c|c|c|c|c|c|c|c|c|c|c|}
\hline \multirow[t]{2}{*}{ Grade } & \multicolumn{2}{|c|}{$\begin{array}{c}K \max 0-I D \perp \\
(n=2 I)\end{array}$} & \multicolumn{2}{|c|}{$\begin{array}{c}K \max I-2 D \\
(n=9)\end{array}$} & \multicolumn{2}{|c|}{$\begin{array}{c}K \max >2 D \\
(n=4)\end{array}$} & \multicolumn{2}{|c|}{$\begin{array}{c}K \max 0-I D \text { I } \\
(n=13)\end{array}$} & \multicolumn{2}{|c|}{$\begin{array}{c}K \max I-2 D \\
(n=9)\end{array}$} & \multicolumn{2}{|c|}{$\begin{array}{c}\text { Total } \\
(n=57)\end{array}$} \\
\hline & rho & $\mathbf{p}$ & rho & $\mathbf{p}$ & rho & p & rho & $\mathbf{p}$ & rho & $\mathbf{p}$ & rho & $\mathbf{p}$ \\
\hline$A$ & 0.279 & 0.221 & 0.105 & 0.788 & 0.624 & 0.376 & -0.374 & 0.207 & -0.385 & 0.271 & 0.482 & $<0.001$ \\
\hline B & -0.051 & 0.826 & 0.038 & 0.922 & -0.900 & 0.100 & -0.244 & 0.422 & 0.500 & 0.141 & -0.055 & 0.681 \\
\hline$C$ & -0.377 & 0.092 & 0.128 & 0.743 & -0.929 & 0.071 & 0.113 & 0.714 & 0.564 & 0.090 & -0.119 & 0.368 \\
\hline
\end{tabular}

Kmax: maximum keratometry.

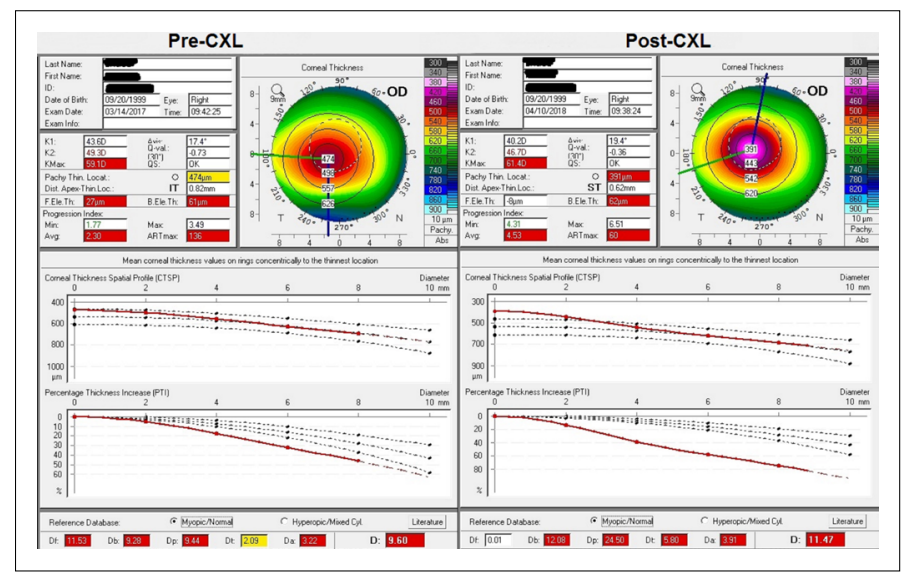

Figure 2. Corneal steepening of $>2 \mathrm{D}$ in the $\mathrm{Kmax} 12$ months after CXL treatment in a case.

\section{Discussion}

Corneal collagen CXL treatment for keratoconus is known to halt or slow down progression of the disease (I5) In this study, the changes in prognostic data obtained from the Scheimpflug system were examined 12 months after CXL treatment for keratoconus. Although several previous studies have made comparisons of standard topographic data pre and post CXL (6-9), there are still some deficiencies in the use of these parameters when evaluating $C X L$ results $(8,16)$.

Due to abnormal corneal steepening in keratoconus, some standard topographic data are not sufficient in the determination of progression and regression. Therefore, progression indexes, such as the BAD display and $A B C D$ grading systems, have been developed (I0). In the present study, 
the Kmax value was taken as the pivot and different indexes were compared over the Kmax. The patients were divided into five different subgroups according to the steepening and flattening degrees of Kmax values as shown in Tables 3 and 4.

In previous studies where conventional CXL treatment has been applied, Wittig-Silva et al. (6) determined $(n=100)$ $1.03 \mathrm{D}$ flattening in the Kmax value in a 3 -year follow-up, Hashemi et al. (7) reported $(n=40) 0.16 \mathrm{D}$ in a 5-year followup, and Chow et al. (17) reported $(n=38)$ I.6 D in a I-year follow-up. The Kmax value is frequently used to determine the progression of the disease. Therefore, to evaluate the accuracy in predicting progression between the two systems, we investigated the relationship of the difference between the initial and final values in the $A B C D$ grading system and the difference between the initial and final Kmax values. In the present study, $(n=57) 0.25 \mathrm{D}$ flattening was determined in the Kmax value, as well as a regression in the $\mathrm{A}$ grade with a significant correlation at the end of one year (Table 5).

Several studies have reported a thinning of the pachymetry measurements obtained from topography in the early period after CXL treatment, but in the late postoperative period, these values have approached the pre-treatment levels $(6$, $18,19)$. Therefore, pachymetric analyses may cause errors in progression analysis after CXL. Similarly, in the present study, progression was determined at 12 months after CXL in the $C$ grade obtained from the pachymin value according to the $A B C D$ grading system. Furthermore, the progression rate in grade $C$ was determined to be greatest in the group with $>2 \mathrm{D}$ flattening in $\mathrm{Kmax}$ (Table 4) (Fig. I). When we analyze the relationship of the differences at the initial and final values between $C$ grade and $K$ max values, the change in $C$ grade in the Kmax $<2 \mathrm{D}$ flattening group approached meaningfulness at most but no significant difference was obtained (Table 5). Hence, the greater amount of pachymetric thinning in this group might have developed as a result of excessive corneal thinning rather than the severity of the disease, as previously reported by Kymonis et al. (20).

At the end of 12 months, anterior surface assessment of $A B C D$ grading parameters showed a 0.19 decrease in the $A$ grade, 0.10 progression in the $B$ grade in the evaluation of the posterior surface, and 0.24 regression was observed in the $D$ grade (Table 2). Just as in the other results, end-points were determined in the $A B C D$ grading system in the group with $>2 \mathrm{D}$ flattening. While there was 0.95 and 0.32 regression in the $A$ and $D$ grades, 0.43 and 0.42 progression was determined in the grade $B$ and $C$ (Table 4). These results showed that excessive anterior surface flattening provided regression at grade $A$.

At 12 months after CXL, there was seen to be a mean reduction of $2.04 \mu \mathrm{m}$ in F.ele.Th and a reduction of 8.01 in ARTmax. These mean data indicated that progression had stopped after $\mathrm{CXL}$ in the anterior surface. In the B.ele.Th value, an increase was determined of $1.61 \mu \mathrm{m}$ in the Kmax $0-I$ D steepening group and $2.75 \mu \mathrm{m}$ in the $>2 \mathrm{D}$ flattening group (Table 3), (Table 4). There have been reports of increased posterior elevation after CXL $(2 \mathrm{I}, 22)$. It is suggested that posterior steepening together with anterior flattening may be the cause for the stabilization of keratometric values after CXL (22). On the other hand, when we analyzed all eyes, there was an increase in the B.ele.Th value but it was not significant. There were studies also analyzing corneal changes after CXL with Scheimpflug imaging that found no significant changes in the posterior elevation $(23,24)$. These differences can be explained by ongoing ectatic changes in the posterior cornea or by the insufficiency of existing devices to analyze posterior corneal elevation after CXL.

When we evaluated according to the change in Kmax value at the end of 12 months, the results of the $0-I D$ and I-2 $D$ flattening groups in particular were seen to be more stable and at levels expected after CXL. Flattening of $>2 D$ in Kmax does not seem to be very reliable in respect of topographic parameters. As seen in the current study, despite the excessive corneal flattening, there was a large fall in ARTmax and signs of progression in the posterior surface evaluation.

The low number of subjects and the short follow-up period were the primary limitations of this study. There is a need for further studies with larger samples so that patients can be grouped according to different stages of keratoconus before $C X L$ to be able to compare progression according to $A B C D$ system.

In conclusion, the anterior corneal surface grade in $A B C D$ system seems to be correlated with Kmax in different groups. However, the posterior elevation was increased and was not correlated with Kmax in I-2 D steepening and $>2 \mathrm{D}$ flattening groups. Although there is an increase in posterior elevation after CXL, despite excessive Kmax flattening, it would be inaccurate to consider this increase as an indicator of topographic progress.

\section{Disclosures}

Ethics Committee Approval: The Ethics Committee of Harran University Faculty of Medicine provided the ethics committee approval for this study (03.05.2018-18/05/2I).

Peer-review: Externally peer-reviewed.

Conflict of Interest: None declared.

Authorship Contributions: Involved in design and conduct of the study (AS, MUI); preparation and review of the study (AS, MUI); data collection (AS, MUI); and statistical analysis (AS, MUI).

\section{References}

I. Rabinowitz YS. Keratoconus. Surv Ophthalmol 1998;42:297319. [CrossRef] 
2. Jhanji V, Sharma N, Vajpayee RB. Management of keratoconus: current scenario. Br J Ophthalmol 20 I I;95:1044-50. [CrossRef]

3. Spoerl E, Huhle M, Seiler T. Induction of cross-links in corneal tissue. Exp Eye Res 1998;66:97-103. [CrossRef]

4. Spoerl E, Wollensak G, Seiler T. Increased resistance of crosslinked cornea against enzymatic digestion. Curr Eye Res 2004;29:35-40. [CrossRef]

5. Wollensak G, Spoerl E, Seiler T. Stress-strain measurements of human and porcine corneas after riboflavin-ultraviolet-A-induced cross-linking. J Cataract Refract Surg 2003;29: I780-5.

6. Wittig-Silva C, Chan E, Islam FM, Wu T, Whiting M, Snibson GR. A randomized, controlled trial of corneal collagen crosslinking in progressive keratoconus: three-year results. Ophthalmology 2014; I2I:8I2-2I. [CrossRef]

7. Hashemi H, Seyedian MA, Miraftab M, Fotouhi A, Asgari S. Corneal collagen cross-linking with riboflavin and ultraviolet a irradiation for keratoconus: long-term results. Ophthalmology 2013;120:1515-20. [CrossRef]

8. Wang YM, Chan TC, Yu MCY, Jhanji V. Comparative evaluation of progression rate in keratoconus before and after collagen crosslinking. Br J Ophthalmol 2018; 102:1 I09-13.

9. Asgari S, Hashemi H. OPD scan III accuracy: Topographic and aberrometric indices after accelerated corneal cross-linking. J Curr Ophthalmol 2017;30:58-62. [CrossRef]

10. Belin MW, Duncan JK. Keratoconus: the ABCD grading system. Klin Monbl Augenheilkd 2016;233:70I-7. [CrossRef]

II. Villavicencio OF, Gilani F, Henriquez MA, Izquierdo L Jr, Ambrósio RR Jr, Belin WM. Independent population validation of the Belin/Ambrosio enhanced ectasia display: Implications for keratoconus studies and screening. Int J Kerat Ect Cor Dis 20।4;3:I-8. [CrossRef]

12. Ambrósio R Jr, Caiado AL, Guerra FP, Louzada R, Sinha RA, Luz A, et al. Novel pachymetric parameters based on corneal tomography for diagnosing keratoconus. J Refract Surg 20I I;27:753-8. [CrossRef]

13. Wollensak G, Spoerl E, Seiler T. Riboflavin/ultraviolet-A-induced collagen crosslinking for the treatment of keratoconus. Am J Ophthalmol 2003;135:620-7. [CrossRef]

14. Mueller A, Thomas BC, Auffarth GU, Holzer MP. Comparison of a new image-guided system versus partial coherence interferometry, Scheimpflug imaging, and optical low-coherence reflectometry devices: keratometry and repeatability. J Cataract Refract Surg 2016;42:672-8. [CrossRef]

15. Wang YM, Chan TCY, Yu M, Jhanji V. Shift in progression rate of keratoconus before and after epithelium-off accelerated corneal collagen crosslinking. J Cataract Refract Surg 2017;43:929-36.

16. Shajari M, Steinwender G, Herrmann K, Kubiak KB, Pavlovic I, Plawetzki E, et al. Evaluation of keratoconus progression. $\mathrm{Br}$ J Ophthalmol 2019;103:55।-7. [CrossRef]

17. Chow VW, Chan TC, Yu M, Wong VW, Jhanji V. One-year outcomes of conventional and accelerated collagen crosslinking in progressive keratoconus. Sci Rep 2015;5:14425. [CrossRef]

18. Uçakhan ÖÖ, Bayraktutar BN, Saglik A. Pediatric corneal collagen cross-linking: long-term follow-up of visual, refractive, and topographic outcomes. Cornea 2016;35:162-8. [CrossRef]

19. Mohammadpour M, Masoumi A, Mirghorbani M, Shahraki K, Hashemi H. Updates on corneal collagen cross-linking: Indications, techniques and clinical outcomes. J Curr Ophthalmol 2017;29:235-47. [CrossRef]

20. Kymionis GD, Tsoulnaras KI, Liakopoulos DA, Paraskevopoulos TA, Kouroupaki Al, Tsilimbaris MK. Excessive corneal flattening and thinning after corneal cross-linking: single-case report with 5-year follow-up. Cornea 20I5;34:704-6. [CrossRef]

2I. Kırgız A, Atalay K, Çabuk KŞ, Kaldırım H, Taşkapılı M. Factors affecting visual acuity after accelerated crosslinking in patients with progressive keratoconus. Arq Bras Oftalmol 2016;79: I5I4. [CrossRef]

22. Steinberg JI, Ahmadiyar M, Rost A, Frings A, Filev F, Katz T, et al. Anterior and posterior corneal changes after crosslinking for keratoconus. Optom Vis Sci 2014;91:I78-86. [CrossRef]

23. Henriquez MA, Izquierdo L Jr, Bernilla C, Zakrzewski PA, Mannis M. Riboflavin/ultraviolet A corneal collagen cross-linking for the treatment of keratoconus: visual outcomes and Scheimpflug analysis. Cornea 201 1;30:281-6. [CrossRef]

24. Grewal DS, Brar GS, Jain R, Sood V, Singla M, Grewal SP. Corneal collagen crosslinking using riboflavin and ultraviolet-A light for keratoconus: one-year analysis using Scheimpflug imaging. J Cataract Refract Surg 2009;35:425-32. [CrossRef] 